\title{
A PEDAGOGIA FREIREANA E SUAS CONTRIBUIÇÕES PARA A EDUCAÇÃO AMBIENTAL NA ESCOLA: A RESISTÊNCIA EM BUSCA DA TRANSFORMAÇÃO DA REALIDADE SOCIOAMBIENTAL
}

\author{
Claudia Lourenço Gomes1 \\ Marília Andrade Torales Campos2 \\ Amerilis de Oliveira Ramos3
}

Resumo: Em tempos de crise na educação, retrocessos e desmontes na Educação Ambiental, considera-se pertinente reavivar alguns princípios e pressupostos político-filosóficos e as contribuições da pedagogia de Paulo Freire. O estudo é de natureza teórica e estabelece um breve diálogo entre a obra Pedagogia da Autonomia, a Teoria da Complexidade e autores do campo da Educação Ambiental para a reflexão desta ação educativa na escola. Freire propõe uma pedagogia capaz de levar os sujeitos a ler, interpretar e transformar as realidades vividas através do processo educativo. A pedagogia libertadora apresentada na obra freireana é entendida como um referencial teórico metodológico para o desenvolvimento da práxis educativa ambiental.

Palavras-chave: Pedagogia Freireana; Escola; Educação Ambiental.

\footnotetext{
1 Universidade Federal do Paraná. E-mail: claudiakak23@gmail.com. Link para o Lattes: http://lattes.cnpq.br/5586287159200738

2 Universidade Federal do Paraná. E-mail: mariliat.ufpr@gmail.com. Link para o Lattes: http://lattes.cnpq.br/7576748068658968

3 Universidade Federal do Paraná. E-mail: almerilisramos@gmail.com. Link para o Lattes: http://lattes.cnpq.br/9664729565529843
}

revista brasileira educação ambiental 
Abstract: In times of crisis in education, setbacks and dismantling in Environmental Education, it is considered pertinent to revive some principles and political-philosophical assumptions and the contributions of Paulo's pedagogy Freire. The study is of a theoretical nature and establishes a brief dialogue between the Pedagogy of Autonomy, Theory of Complexity and authors from the field from environmental education to the reflection of this educational action at school. Freire proposes a pedagogy capable of leading subjects to read, interpret and transform the realities experienced through the educational process. The pedagogy liberator presented in the Freirean work is understood as a referential methodological theoretical framework for the development of environmental educational praxis.

Keywords: Freirean Pedagogy; School; Environmental Education.

\section{Introdução}

A humanidade tem vivenciado no último século um desenvolvimento econômico sem precedentes. Essas mudanças se deram por meio da capacidade humana de dominar e organizar o meio ambiente em função de suas necessidades. A ciência e a educação como promotoras do progresso social e econômico deparam-se atualmente com um modelo de crescimento que se confronta com os limites que os recursos naturais comportam, sendo elas convidadas a trazer respostas e buscar soluções para a problemática socioambiental vivida.

As transformações e as discussões no que diz respeito às relações estabelecidas entre os seres humanos e a natureza, o desenvolvimento em larga escala, o uso dos recursos naturais de forma desequilibrada, colocam em xeque a sustentabilidade da Terra e a sobrevivência da vida no planeta. $O$ século XXI diante das emergências sociais exige da educação escolar e de todos os seres humanos uma grande capacidade de autonomia e discernimento da crise presente, através da formação da responsabilidade individual que pertence a cada sujeito na realização de um destino coletivo transformador.

Ao considerar que a educação ao longo da história propõe e define tipos de indivíduos a serem formados, quais sociedades serão construídas e, partindo do pressuposto de que todos os seres humanos são alvo do processo educacional que se estende por toda à vida, torna-se necessário ultrapassar a visão de educação utilitarista e bancária para uma educação para o sujeito cidadão, inacabado, pertencente a uma sociedade, que ocupa um endereço na história e que possui um lugar no universo.

Diante da crise econômica e política, dos diversos desafios, da incerteza do futuro, a educação surge como esperança, instrumento indispensável à humanidade na busca da justiça social e do desenvolvimento social harmonioso e equilibrado com o meio ambiente. 
O presente trabalho traz algumas contribuições do pensamento pedagógico de Paulo Freire e o seu potencial iluminador para a dimensão crítica da Educação Ambiental, em busca de uma educação que esteja engajada na tarefa reflexiva, implicando nos sujeitos cognoscentes outras leituras da vida, novas versões possíveis sobre o mundo e sua ação sobre ele.

Assim, este escrito propõe um diálogo entre a obra freireana Pedagogia da Autonomia (FREIRE, 1996), os autores Pernambuco e Silva (2006); alguns autores do campo da Educação Ambiental (CAPRA, 1996; CARVALHO, 2004; LEFF, 2001; LOUREIRO, 2019; TORALES, 2013) e da Teoria da Complexidade (MORIN, 2002; SÁ, CARNEIRO, ASINELLI, 2013) para o desenvolvimento de uma formação educativa com proposta de formar indivíduos capazes de ler seu meio ambiente e interpretar as relações existentes, os conflitos, os impasses, os problemas presentes e elaborar caminhos possíveis.

Oferecem-se, assim, condições para que os sujeitos aprendentes e ensinantes compreendam a problemática da existência humana e sua relação com a natureza de forma crítica e reflexiva, ou seja, formar indivíduos capazes de "ler e interpretar" o mundo complexo, em constantes mudanças. Uma educação comprometida com a construção da consciência crítica, um pensamento certo e reflexivo, que contribua para a melhor análise dos indivíduos acerca da realidade vivida, das complexas e múltiplas relações, tornando-os capazes de agir sobre ela com autonomia e transformá-la.

Frente à intensificação da crise política e econômica, da crise da educação, os desmontes e retrocessos, em especial da Educação Ambiental e a condenação equivocada da contribuição do pensamento de Paulo Freire à educação brasileira, reviver os princípios e pressupostos político-filosóficos traz ao diálogo a reflexão sobre a importância da ação educativa transformadora de sociedade e de mundo, além de se manifestar como um ato de resistência a qualquer forma de opressão e injustiça social.

Em face das crises que se apresentam ao longo a história e se intensificam no atual contexto, é fundamental que a escola, por intermédio dos profissionais da educação e do desenvolvimento da Educação Ambiental, busque subsídios para uma prática educativa comprometida com a formação crítica e emancipatória, possibilitando que os estudantes possam compreender e atuar a fim de transformar a realidade complexa e multifacetada.

\section{Educação Ambiental e diálogos com Paulo Freire: uma educação voltada para a transformação da realidade socioambiental}

A grave situação do planeta em relação à deterioração ambiental e à crise societária estão evidentes e bárbaras. O coletivo humano, historicamente, tornou-se agente promotor da transformação social e ambiental que vestiu o homem com a fantasia da onipotência, tomando conta das suas concepções de 
vida, submetendo a sociedade a vivenciar as catástrofes ambientais e as injustiças sociais.

Atualmente, a relação ser humano/sociedade/natureza exige uma nova visão de mundo, que seja crítica, reflexiva, responsável, consciente e transformadora (FREIRE, 1996); capaz de compreender as totalidades distintas e os complexos relacionais (CAPRA, 1996; MORIN, 2002; SÁ, CARNEIRO, LUZ, 2013) e romper com a alienação e indiferença na relação com o outro (LOUREIRO, 2019). Reconhecida socialmente como instituição responsável por aprendizagens, que se realiza através de práticas educativas planejadas e sistemáticas, contínua e duradoura na vida das pessoas, emerge a necessidade de a escola inserir/potencializar a Educação Ambiental no universo escolar (TORALES, 2013).

Torna-se necessário buscar novas relações socioambientais, que atuem criticamente superando as relações sociais vigentes, fazendo rupturas com os padrões dominadores de desapropriação da natureza e os modelos opressores de sociedade, que caracterizam a contemporaneidade marcada pelo capitalismo.

Cabe, então, ao processo educacional, as instituições de ensino, a comunidade escolar assumir o papel político, não neutro e desafiador de trazer conhecimentos e fazeres para atuar na realidade socioambiental, já que cada vez mais intensificam as desigualdades sociais e se complexificam os problemas ambientais que estão colocando em risco a manutenção e a sobrevivência da diversidade de vida no planeta.

A Educação Ambiental, compreendida como um movimento contracultura, aliada à pedagogia de Freire tem potencialmente a possibilidade de contribuir para reflexão crítica das demandas emergentes no contexto socioambiental e, consequentemente, para mudanças nas práticas sociais.

Uma prática educativa emancipatória, que tem por finalidade a transformação socioambiental, é uma Educação Ambiental politizada, o que exige dos sujeitos posicionamento quanto ao projeto de sociedade e de sustentabilidade que desejam. E, posicionar-se leva à presença e a uma atitude reflexiva da realidade, à compreensão complexa das responsabilidades e direitos dos sujeitos, seus grupos/classes, a uma experiência que atue tanto no cotidiano quanto na organização política (LOUREIRO, 2019).

Segundo Freire (1996, p. 74), "ninguém pode estar no mundo, com o mundo e com os outros de forma neutra. Não posso estar no mundo de luvas nas mãos constatando apenas. $A$ acomodação em mim é apenas caminho para a inserção, que implica decisão, escolha, intervenção na realidade".

Entendendo que as instituições de ensino são promotoras da formação de pessoas, elas passam a ser reconhecidas como um espaço privilegiado para a construção de uma curiosidade epistemológica que seja reflexiva e crítica. Espaços nos quais indivíduos constroem pensamentos, opiniões, questionamentos, comportamentos e atitudes. 
Neste viés, a pedagogia progressista de Paulo Freire e a Educação Ambiental no contexto escolar, junto com as diferentes áreas do conhecimento humano e a formação do professor, devem ser compreendidas como fios condutores na formação de sujeitos protagonistas das transformações históricas, da realidade social e ambiental que a humanidade vivencia e tanto necessita. Neste pensar, Freire (1996, p. 27) nos lembra de que "esta é a vantagem dos seres humanos - a de se terem tornado capazes de ir além de seus condicionamentos".

A sociedade contemporânea está sendo confrontada com a problemática que envolve a maneira do homem se relacionar com a natureza, consequentemente colocando em crise sua concepção. Desta forma, torna-se imprescindível que a atual sociedade faça uma ruptura com o paradigma dominador existente, com o modelo de desenvolvimento que separa o homem da natureza e que desconsidera que tudo está tecido junto, formando a teia da vida, conforme apontado por Capra (1996).

Este pressuposto é reafirmado pela Teoria da Complexidade de Morin (2002), quando nos traz que é necessária uma compreensão de totalidade, de inteireza, sendo formada pelo todo e as partes interconectadas, levando à compreensão de um permanente estado de relação entre os indivíduos, a sociedade e o contexto.

$\mathrm{Na}$ ótica da complexidade, o meio ambiente não se caracteriza apenas em sua categoria biológica, mas também, como aponta Leff (2001, p. 224), "uma racionalidade social, configurada por comportamentos, valores e saberes". Reconhecendo que se vive uma emergência mais do que ecológica, senão também uma crise de pensamento causada pelo processo de transformação da sociedade, é indispensável desenvolver um referencial educativo capaz de apontar para uma nova racionalidade ambiental, capaz de subverter a ordem imperante entre as lógicas da vida e o destino das sociedades (LEFF, 2001).

Refletir sobre a complexidade ambiental abre espaço para compreender a ação do ato educativo na formação de novos atores sociais, que se mobilizam em prol da vida, para um processo educativo articulado, compromissado e participativo. Tal atitude implica em novas formas de ler e interpretar o mundo, de pensar, de ser, de agir, de modificar, de ser presença; uma transformação de conhecimentos e de novas práticas educativas.

Carvalho (2004) compreende a Educação Ambiental como um projeto de cidadania, ampliada pela dimensão ambiental, que propõe uma mediação de alto potencial na construção da sociedade. Torales (2013, p. 2) considera a Educação Ambiental como uma "dimensão pedagógica e política na medida em que oportuniza o debate, o questionamento e a negociação de projetos políticos, culturais e sociais".

Isso implica em processos dialógicos, outras formas de orientar as gerações atuais e futuras, para que enxerguem a realidade como um todo e 
não separadamente. Atitudes pedagógicas que rompam com o pensamento linear e levem os educandos ao desafio de encontrar novos caminhos possíveis e, como seres inacabados, capazes de ser mais (FREIRE, 1996).

Imaginamos e defendemos a possibilidade de que o desenvolvimento desse processo pode se dar por meio de uma pedagogia libertadora, da autonomia e da Educação Ambiental. De acordo com Paulo Freire (1996, p. 42), o ser humano deve "assumir-se como ser social e histórico, como ser pensante, comunicante, transformador, criador, realizador de sonhos".

Diante do exposto, Paulo Freire tem muito a contribuir para o desenvolvimento da Educação Ambiental na escola, uma vez que seu pensar está no social, na compreensão do inacabamento humano, na capacidade de ser mais, de ir além, de problematizar o contexto, de ler e interpretar o mundo e de transformá-lo.

Pois, para Freire, é necessário conhecer criticamente a realidade para transformá-la, conhecer para projetar mudanças; que, pelo diálogo, educador e educando, em torno da realidade problematizada da vida e suas inter-relações, vá transformando a curiosidade ingênua em curiosidade epistemológica, baseando a construção de conhecimentos e alternativas para melhorar a qualidade das relações estabelecidas. Desenvolvendo, desta forma, com os sujeitos, um potencial emancipatório e a instituição de uma práxis das temáticas ambientais, para um aprendizado de exercício permanente de aprimoramento da conscientização do sujeito no mundo, buscando uma cidadania ambiental.

Sobre o pensar crítico, reflexivo e emancipatório presente na pedagogia de Paulo Freire, o ato de educar se dá a partir da realidade espacial, social e histórica da vida; educar é problematizar e não só problematizar, mas buscar a superação dos problemas, ultrapassando visões simplistas e ingênuas de educação. Como aponta a contribuição de Loureiro (2019, p. 84), "a historicidade passa a ser constitutiva da atividade pedagógica, não cabendo mais como suficiente a constatação do problema ou o voluntarismo para resolvê-lo, sendo vital a problematização que leve o conhecimento da sua dinâmica causal e dos agentes sociais envolvidos".

Neste olhar, educar, e educar ambientalmente, é um ato coberto de intencionalidades, pois se trata de um ato político e esperançoso, que compreende que o futuro e o caos ambiental é desafiador, mas que os seres humanos que se reconhecem no mundo como seres históricos e sociais se tornam capazes de decidir, romper e transformar a realidade social e ambiental, que na atual conjuntura política brasileira se manifesta pelos desmontes à educação e da Educação Ambiental, por um modelo opressor de Estado, que viabiliza a intensificação da degradação ambiental e acentuando as desigualdades sociais.

Pernambuco e Silva (2006, p. 210) afirmam que, 
Ter como parâmetro o pensamento de Paulo Freire significa buscar, eticamente, práticas de convivência social em que as relações socioculturais e econômicas não se dão mais de forma hierarquizada, mas com o objetivo de possibilitar novas articulações entre os sujeitos históricos contextualizados, na construção de projetos coletivos de reação à desigualdade e a exclusão social. Isso demanda a construção de novos conhecimentos e formas críticas de intervenção na realidade.

Para Loureiro (2019, p. 94), "em tempos históricos de agudas crises societárias, é preciso saber de que lado se está na história e se a Educação Ambiental se fará no sentido das transformações sociais necessárias à vida em sua pujança e diversidade".

Perante os conflitos socioambientais, do mercado do lucro, da disjunção homem/natureza, da exploração dos recursos naturais e dos homens pelos homens, da insignificância do outro, do ter mais e mais, do sacrifício das diferentes formas de vida, das incertezas dos caminhos futuros, a Educação Ambiental baseada em Paulo Freire é um ato de esperança.

Diante do que brevemente que foi exposto, visto que a pedagogia freiriana não se esgota nas afirmações supracitadas, a organização escolar necessita se mover e buscar estratégias pedagógicas, uma práxis educativa que pensa e problematiza a realidade em sua complexidade, levando a escola a assumir uma posição político-pedagógica que se propõe a formar cidadãos éticos e conscientes de que mudar é possível.

Ao reconhecer que a Educação Ambiental é educação e, portanto, é intervir no mundo (Freire, 1996) e que a escola como instituição social contribui para a formação de sociedades. Entendemos que ela necessita se envolver na tarefa de elevar a capacidade intelectual dos sujeitos, buscando caminhos possíveis que efetivamente proponham transformações socioculturais e ambientais, que tenham como princípios político-pedagógicos a construção de uma sociedade justa e sustentável.

\section{Conclusões}

Diante da problemática da realidade socioambiental experimentada pela sociedade contemporânea, torna-se emergente uma educação voltada às questões ambientais, uma educação capaz de levar os sujeitos a refletir sobre sua existência, seu inacabamento, sua função social e histórica. O modelo de desenvolvimento capitalista e regulador do comportamento humano exige um novo olhar sobre a relação homem/sociedade/natureza, um olhar capaz de elevar a compreensão humana sobre os conflitos vividos, que se dará através da Educação Ambiental. Pois esta forma de educar está comprometida política e ideologicamente com a transformação da sociedade, que faz ruptura com a visão hegemônica e dominadora do mercado em busca da justiça social e ambiental. 
A Educação Ambiental trata-se de uma educação com alto potencial crítico e transformador, em que o educando se percebe como sujeito, sensibilizado pelo saber ambiental, que se reconhece como ser político pela presença no mundo, que ocupa um lugar no universo e que, reconhecendo-se como capaz de ir além, pega seu destino em suas mãos e, de posse da curiosidade epistemológica, assume responsabilidades, tornando-se um ser ativo, participante, que toma decisões e faz intervenções com vistas à manutenção e defesa da justiça social e das diferentes formas de vida.

Paulo Freire e o seu pensar pedagógico, que tem como pressuposto o ser humano como sujeito transformador, para a formação de homens e mulheres emancipados que, com conhecimento, tornam-se livres; são fundamentais para a Educação Ambiental e para a prática educativa na escola, pois reconhecem 0 ato de educar como uma intervenção social para a transformação da realidade. Um ato de ação-reflexão-ação em prol da formação responsável, do desenvolvimento integral dos sujeitos éticos universalmente e de cidadãos politizados para com a realidade e os problemas do mundo. Esse sujeito freireano que, através do conhecimento ambiental, faz a leitura do mundo e o transforma.

\section{Referências}

CAPRA, F. A teia da vida: uma nova compreensão científica dos sistemas vivos. São Paulo: Cultrix, 1996.

CARVALHO, I.C.M. Educação Ambiental: a formação o sujeito ecológico. São Paulo: Cortez, 2004.

FREIRE, P. Pedagogia as autonomia: saberes necessários à prática educativa. São Paulo: Paz e Terra, 1996.

LOUREIRO, C.F.B. Questões ontológicas e metodológicas da Educação Ambiental crítica no capitalismo contemporâneo. REMEA - Revista Eletrônica do Mestrado em Educação Ambiental, [S.I.], v. 36, n. 1, p. 79-95, maio 2019.

LEFF, H. Epistemologia ambiental. São Paulo: Cortez, 2001.

MORIN, E. Os sete saberes necessários à educação do futuro. São Paulo: Cortez, 2002.

PERNAMBUCO, M.M.; SILVA, A.F.G. Paulo Freire: a educação e a transformação do mundo. In: CARVALHO, I.C.M.; GRÜN, M.; TRAJBER, R. (Org.). Pensar o Ambiente: bases filosóficas para a Educação Ambiental. Brasília: Ministério da Educação, SECAD, UNESCO, 2006.

SÁ, R.A.; CARNEIRO, S.M.; LUZ, A.A. A escola e os sete saberes: reflexões para avanços inovadores no processo educativo. Revista da FAEEBA Educação e Contemporaneidade, Salvador, v. 22, n. 39, p. 159-169, 2013.

TORALES, M.A. A inserção da Educação Ambiental nos currículos escolares e o papel dos professores: da ação escolar a ação educativo-comunitária como compromisso político-ideológico. REMEA - Revista Eletrônica do Mestrado em Educação Ambiental, [S.I.], p. 1-17, mar. 2013. 